\title{
Restoration Survival: Revisiting Patients' Risk Factors Through a Systematic Literature Review
}

\author{
FH van de Sande $\bullet \mathrm{K}$ Collares $\bullet \mathrm{MB}$ Correa \\ MS Cenci $\bullet$ FF Demarco $\bullet$ NJM Opdam
}

\begin{abstract}
Clinical Relevance
An objective description of patients' factors should become available in clinical studies, since their contribution to restoration survival cannot be ignored and may assist clinical decision making in challenging situations.
\end{abstract}

\section{SUMMARY}

A literature review was conducted to investigate the influence of patient-related factors on restoration survival in posterior permanent teeth as well as to report the methods used to collect these factors. The selection of articles

*Françoise $\mathrm{H}$ van de Sande, DDS, MSc, PhD, School of Dentistry, IMED Faculdade Meridional Restorative Dentistry, RS, Brazil

Kauê Collares, DDS, Federal University of Pelotas, Graduate Program in Dentistry, RS, Brazil

Marcos B Correa, DDS, MSc, PhD, Federal University of Pelotas, Department of Operative Dentistry, RS, Brazil

Maximiliano S Cenci, DDS, MSc, PhD, Graduate Program in Dentistry, Federal University of Pelotas, Department of Operative Dentistry, RS, Brazil

Flávio F Demarco, DDS, PhD, Federal University of Pelotas, Department of Operative Dentistry, RS, Brazil

Niek JM Opdam, ad hoc reviewer, PhD, DDS, Radboud University Medical Centre, Preventive and Restorative Dentistry, Nijmegen, the Netherlands

*Corresponding author: Rua Senador Pinheiro, 304 Passo Fundo, RS 99070-220 Brazil; e-mail: fvandesande@gmail. com

DOI: $10.2341 / 15-120-\mathrm{LIT}$ on longitudinal clinical studies investigating the survival of posterior restorations (except full crowns and temporary fillings) and including patient-related factors was performed by applying predefined criteria. The review was organized into two parts, the first describing how patient factors were assessed in the studies $(n=45)$ and the second presenting the statistical significance $(n=27)$ and size of the effect $(n=11)$ of these factors on restoration survival. Patient-related factors mentioned in the studies included age; gender; caries risk; caries activity/severity; decayed, missing, filled teeth; number of restorations; oral hygiene; and bruxism, among others. Sixteen studies included the patient age or age range in the analysis, which was found to be significant in $47 \%$ of the studies. Regarding gender, four of 17 reports found a significant effect on survival, showing more failures for men in three studies. The caries risk profile or related variables were included in the analysis of $\mathbf{1 5}$ studies, and a significant effect on survival was reported for high-caries-risk individuals (or related variables) in $67 \%$ of these studies. Bruxism was also found to influence restora- 
tion survival in three of six studies where this variable was investigated. Some issues were found regarding the reporting of methods used to classify patients according to risk and were thoroughly discussed. In view of the information gathered in this review, the assessment of patient factors along with other variables should become part of clinical studies investigating restoration survival, since several of these factors were shown to influence the failure of restorations, regardless of the material type.

\section{INTRODUCTION}

Even though a decrease in the worldwide prevalence of caries has been observed, untreated dental caries in permanent teeth is highly prevalent, affecting about $35 \%$ of the world population, ${ }^{1}$ especially in posterior teeth. There are several different options to perform posterior restorations, including direct materials (amalgam, composite) and indirect materials (composite, ceramic, metal). The selection, by the clinician, for a particular material and technique to restore posterior teeth may be influenced by the dentist's personal preferences and skills, patient requests and financial resources, and country policies, among others. ${ }^{2-5}$ Considering this background information, the decision is ultimately based in the belief of providing the most appropriate and long-lasting treatment according to the patient's needs.

However, the precise indication of the treatment modality, verified through long-term survival of restoration and tooth, is hard to establish based on high-quality evidence. ${ }^{6}$ Also, clinical trials investigating the survival of restorations are frequently focused in the comparison of materials or technical procedures, ${ }^{7-9}$ while other factors that are crucial for clinical decision making are scarcely examined. The selection of patients to comply with the inclusion/ exclusion criteria gives these studies high internal validity but low external validity, making results more difficult to be translated to the daily clinical practice. ${ }^{10}$ Regardless of material/technique, in some clinical studies in which patients were not particularly selected for inclusion, it was observed that failures were related to certain patients. ${ }^{11-14} \mathrm{~Pa}-$ tient-related factors such as caries risk and bruxism have been associated with the main reasons for failure for composite resin restorations in posterior teeth $^{10}$ and were found to influence restoration survival in retrospective studies. ${ }^{15,16}$ Likewise, when examined, patient-related factors seem to negatively affect the survival of other restorative procedures, including ceramic and amalgam restorations. ${ }^{17-21}$ Thus, investigations on restoration survival should include patient factors in the analysis to assist with the process of basing clinical decision making on more predictable outcomes and also for patient awareness.

On the other hand, determining the effect of patients and their related variables presents several difficulties. Straightforward variables such as gender; age; and decayed, missing, and filled teeth (DMFT) can be easily collected, whereas others, such as caries risk and bruxism, may heavily depend on the collection method and criteria applied. Therefore, the aims of the present review were to investigate the influence of patient-related factors on restoration survival as well as to report the methods used to collect these factors.

\section{METHODS AND MATERIALS}

\section{Search}

The search for articles was performed in PubMed/ Medline, Scopus, and Cochrane Library databases. The search strategy was constructed by using controlled vocabulary and free terms around the terms dental restoration, amalgam, composite resin, inlays, onlay, survival, longevity, dental restoration failure, posterior teeth, clinical trial, clinical evaluation, longitudinal study, retrospective study, and follow-up. The search was performed in April 2014, and an automatic update was scheduled in the PubMed database up to the completion of this review, in April 2015.

\section{Eligibility Criteria}

For inclusion, full-text articles published in English, with the characteristics presented below, were considered:

- Longitudinal clinical studies, prospective and retrospective

- Posterior permanent teeth

- Direct and indirect restorations, class I, class II, inlay, onlay, overlay, and partial crown

- Amalgam, composite resins (direct and indirect), ceramics

- Three-year minimum follow-up period

- Information regarding patient factors (caries risk, bruxism, DMFT, etc) of the study population, including the criteria applied and/or the effect of patient factors (age, gender, caries risk, bruxism, DMFT, etc) on restoration survival 
- Outcome: Cumulative restoration survival (percentage) or annual failure rate (AFR\%) or information in text to allow the calculation (number of restorations evaluated and failed/replaced/repaired for a given period of time; life tables)

Studies not presenting the above-mentioned characteristics or presenting different outcome measurements (eg, median survival time) were not considered for this review. Studies presenting the above-mentioned characteristics and also including anterior teeth, primary teeth, post systems, full crowns, or different restorative materials were excluded if the outcome was not reported separately.

\section{Study Selection}

All retrieved titles were stored and managed in EndNote X7 software (Thomson Reuters, San Francisco, CA, USA). The articles identified in all databases were screened for duplicates that were automatically excluded. Titles and abstracts were screened by two reviewers (F.H.S., K.C.) independently. If the abstract was missing, the full-text article was subjected to appraisal. Disagreements were identified and discussed until a consensus was reached. References of eligible articles and reviews on restoration survival were hand searched to detect other potential studies of interest, which were screened in the same way.

\section{Evaluation}

The articles meeting the inclusion criteria were subjected to critical appraisal, which was carried out by one reviewer (F.H.S.) and checked by another (K.C.). Data were extracted using a pilottested table, in duplicate, and included country, clinical setting, study design, follow-up period, number of patients included, drop out, patientrelated factors, number of operators, number of restorations originally included and followed, restorative material type, cavity design or number of restored surfaces, tooth, survival/AFR\%, factors influencing restoration survival, size of the effect of patient-related variables, and statistical analysis performed. The survival/AFR\% was either extracted from the article or calculated by the authors of this review according to information given on live tables or on length of follow-up and number of restorations evaluated and failed. To estimate the mean AFR\% of the restorations, the following formula was applied: $(1-y) z=(1-x)$, in which $y$ expresses the AFR and $x$ the total failure in $z$ years. $^{22}$

\section{Data Synthesis and Management}

Data collection was organized into two separate parts for analysis. First, articles reporting on patient-related factors were searched for the criteria applied to classify the individuals into groups. This information was organized into one table according to the reported patient factors. For the second part, only studies that included patient factors in the analysis of the outcome (restoration survival, failure rate/failure distribution) were selected. Detailed information of these studies was organized into tables, including the significance of all investigated variables and the size of the effect for patient-related variables (when available). Some of the included studies had data on restorations placed in anterior teeth, primary teeth, and full crowns. In such cases, the extraction of data for the present review did not include those samples.

\section{RESULTS}

In total, 1048 titles were found in PubMed, 2186 in Scopus, and 40 in Cochrane Library, resulting in 3274 records identified in the databases, of which 366 were duplicates that were removed. After title and abstract screening, 239 full-text articles were assessed for eligibility, resulting in 51 studies included for data extraction. Forty-five articles included the assessment of patient factors and were selected for the first part of the review, and 27 of these studies included the analysis of patient factors in the outcome and qualified for the second part of the review.

\section{Methods to Assess Patient Risk (Part 1)}

Studies addressing patient-related factors and the methods used by the authors to assess the individuals are described in Table 1 and included caries risk, caries activity, caries severity, number of restorations, oral hygiene or oral health, salivary parameters and bacterial levels, bruxism/parafunctional habits, erosion, periodontal status, attrition of the tooth structure, and smoking habits. Twenty-six studies reported to have assessed the caries risk of the patients, which was based, in most of the reports, in the present/past caries experience. ${ }^{15,16,22-33,36,42,43}$ Objective parameters for defining the caries risk profile were often set according to the number of new caries lesions leading to restorations in a definite period of time. In this sense, a high caries risk was established when one or more new lesions occurred per year in Opdam and others $(2010)^{22}$ or two or more in a three-year period in van de Sande and others (2013). ${ }^{15}$ In Jokstad and Mjor $(1991)^{42}$ and 
\begin{tabular}{|l}
\hline Table 1: Description of Methods Presented \\
\hline Caries Risk \\
\hline Opdam and others (2007), ${ }^{16}$ van Dijken \\
(2003), ${ }^{23}$ van Dijken $(2010),{ }^{24}$ van Dijken \\
and others (1999), ${ }^{25}$ van Dijken and \\
Lindberg (2009), ${ }^{6}$ van Dijken and Pallesen \\
(2011), ${ }^{27}$ van Dijken and Pallesen (2013), \\
van Dijken (2013), ${ }^{29}$ van Dijken and \\
Sunnegardh-Gronberg (2005) ${ }^{30}$ van Dijken \\
and Sunnegardh-Gronberg (2006), ${ }^{31}$ Sjogren \\
and others (2004), ${ }^{32}$ Lindberg and others \\
(2007), ${ }^{33}$ Andersson-Wenckert and others \\
(2004), ${ }^{34}$ Van Dijken and Sunnegardh- \\
Gronberg (2005) ${ }^{35}$ \\
\hline Fasbinder and others (2005) ${ }^{36}$
\end{tabular}

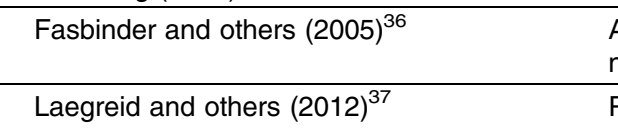

Laegreid and others (2012)

Opdam and others $(2010)^{22}$

van de Sande and others $(2013)^{15}$

van Dijken (2000), ${ }^{13}$ van Dijken (1991), ${ }^{38}$ van Dijken (1994), ${ }^{39}$ van Dijken and others (1998), ${ }^{40}$ Aberg and others (1994) ${ }^{41}$

\begin{tabular}{|l}
\hline Caries activity \\
\hline Jokstad and Mjor (1991) \\
\hline
\end{tabular}

Jokstad and $M$ jor $(1991)^{42}$

Nordbo and others $(1998)^{43}$
Suni and others $(2013)^{44}$

Caries severity

Kopperud and others $(2012)^{45}$

Number of restorations

Kubo and others (2011) ${ }^{46}$

Opdam and others (2007), ${ }^{47}$ Pallesen and $\quad$ Number of restorations per patient during a defined period of time

others $(2013)^{48}$

Soncini and others $(2007)^{49} \quad$ Number of restorations

Oral hygiene or oral health

Al-Samhan and others $(2010)^{50}$
The caries risk for each patient at baseline was estimated by the treating clinician by means of clinical and sociodemographic information routinely available at the annual clinical examinations (eg, incipient caries lesions and former caries history)

At baseline: number of restorations the patient reported having received in the previous 12 mo; low caries risk, $\leq 1$; moderate caries risk, 2 and 3 ; and high caries risk, $\geq 4$

Patient-related factors such as general health; dietary habits; decay, missing, filled teeth; oral hygiene; saliva (quality, quantity); and use of fluoride were measured and given a score according to a predetermined scale and then entered into Cariogram. Then, they were categorized according to severity: very high, high, medium, low, and very low caries risk corresponding to $0 \%-20 \%, 29 \%-40 \%, 41 \%-60 \%, 61 \%-80 \%$, and $81 \%-100 \%$ chance of avoiding caries.

The history of new lesions over the entire period was assessed by the clinician. Patients arriving in the practice with caries lesions but who in subsequent years did not show high caries activity were assessed as "low risk." Patients who continued to show, yearly, one or more new caries lesions during the entire period were assessed as "high risk."

Based on the patient history. In the first $3 \mathrm{y}$ after placement of the restoration, the records were inspected for the presence of a new caries lesion detected from bitewing radiographs and resulting in placement of a restoration. When more than one of these events happened in the three-year period after restoration placement, the patient was assessed as high caries risk. In all other cases, the patient was assessed as low risk.

Evaluation of six negative factors. Oral hygiene- plaque score or gingival bleeding on more than $30 \%$ of the tooth surfaces. Intake of fermentable carbohydrates with a mean of six times or more per day, registered during four days. The presence of more than $2.5 \times 10^{5} \mathrm{CFU} / \mathrm{mL}$ saliva of Streptococcus mutans or $10^{5} \mathrm{CFU} / \mathrm{mL}$ saliva of lactobacilli. Buffer values of 5.5 or lower and a flow rate of $0.7 \mathrm{~mL} / \mathrm{min}$ or less. Patients with three or more negative factors were considered at high caries risk.

Based on the incidence of primary or secondary caries during the first eight years of the trial period. Low caries activity: $\leq 0.5$ new restorations per year; high caries activity: $\geq$ two new restorations per year.

Based in radiographs and dental records. High activity: >two new lesions per year.

Patients were divided into caries-active and caries-resistant persons according to their past caries experience in any of the first molars before age eight (caries prone) or after 10 years (caries resistant), with the rest forming an intermedial group.

Primary caries grades: $1=$ radiolucency confined to the outer half and $2=$ the inner half of the enamel; $3=$ radiolucency confined to the outer third, $4=$ to the middle third, or $5=$ to the inner third of the dentin

Retreatment risk: clinical history at the last visit, low (no restorations placed during the past 3 $\mathrm{y}$ ), medium (one or two restorations placed during the past $3 \mathrm{y}$ ), and high (three or more restorations placed during the past $3 \mathrm{y}$ )

The presence of plaque was determined on teeth surfaces by a staining solution. The patients' oral hygiene was determined as good or poor based on their plaque score; $30 \%$ or above (note the authors probably meant $30 \%$ or below) was considered as having good oral hygiene. 
Table 1: Description of Methods Presented in the Studies Regarding the Assessment of Patient Factors (cont.)

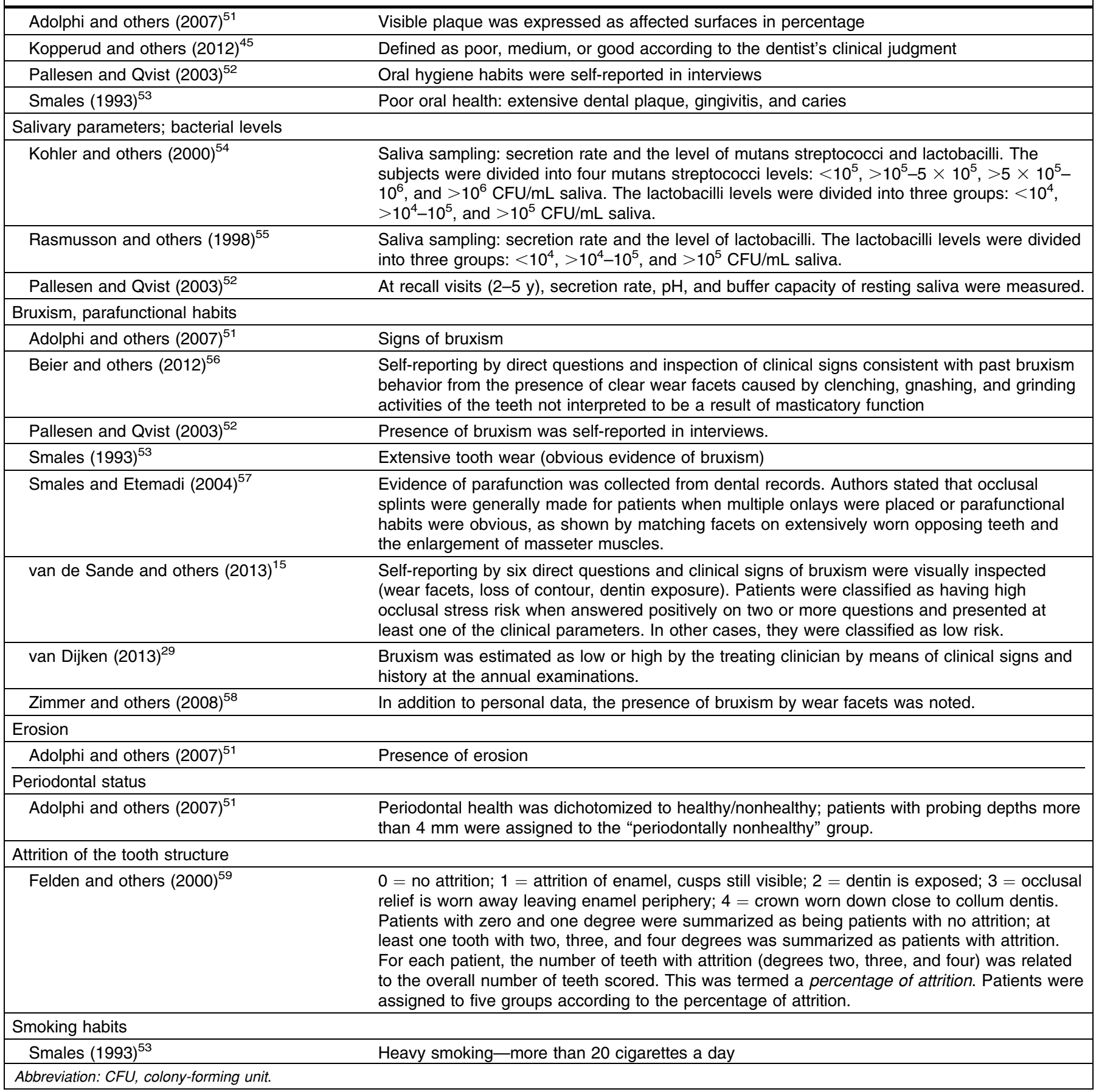

Nordbo and others (1998), ${ }^{43}$ a high caries risk was determined when two or more lesions occurred per year, while in Fasbinder and others $(2005),{ }^{36}$ the placement of four or more restorations in the previous year should have been reported by the patient. In several articles, the caries risk was reported to have been estimated by the treating clinician by the evaluation of clinical information regarding incipient caries lesions and former caries histories as well as sociodemographic data. ${ }^{16,24-35}$ The study of Laegreid and others $(2012)^{37}$ was the only one reporting the use of a caries-risk assessment computer software tool (Cariogram Program ${ }^{60}$ ) to classify the patients into risk groups. Although not using a specific tool, van Dijken $(1991,1994),{ }^{38,39}$ van Dijken and others (1998), ${ }^{40}$ Aberg and others 
(1994) ${ }^{41}$ and Pallesen and Qvist $(2003)^{52}$ reported a number of indicators that were taken into account to determine the caries risk, such as oral hygiene, intake of fermentable carbohydrates, salivary microbial counts, salivary flow rates, and buffer values. In these studies, patients presenting three or more out of six negative factors were assessed as high caries risk. Other variables that can be related to the caries risk of the patient were also used, such as DMFT/ $\mathrm{DFT},{ }^{19,45,61}$ number of total or new restorations per patient, ${ }^{46-49}$ caries severity, ${ }^{45}$ caries experience at earlier ages, ${ }^{44}$ salivary parameters, and microbiologic counts. ${ }^{54,55}$

The assessment of bruxism or parafunctional habits in the study populations was mentioned in nine reports. ${ }^{15,29,51-53,56-58,62}$ When stated, the methods used to estimate this condition were based in the examination of clinical signs (eg, wear facets) $15,29,53,56,58$ and by self-report questionnaires. ${ }^{15,52,56}$

Gender was investigated in several reports, ${ }^{*}$ as well as was the age or age range of the patients. ${ }^{\dagger}$ A few other patient-related factors were mentioned in the studies with lower frequencies, namely, erosion and periodontal status, ${ }^{58}$ attrition, ${ }^{59}$ oral health, oral hygiene or plaque levels, ${ }^{45,51-53,63}$ socioeconomic status, ${ }^{49}$ and smoking habits. ${ }^{53}$

\section{Effect of Patient Risk Factors in Restoration Survival (Part 2)}

Characteristics of the Studies-The effect of patient-related variables on survival of restorations, along with other variables, was investigated in 27 studies. General characteristics of the studies are presented in Table 2, and detailed information is presented in Table 3. Studies were grouped according to the restorative material used and included amalgam (six studies), ${ }^{19,42,53,64,68,69}$ amalgam and composite resin (three studies), ${ }^{22,47,49}$ composite resin (10 studies), ${ }^{\ddagger}$ sandwich restorations (two studies), ${ }^{16,34}$ and ceramics (six studies). ${ }^{56-58,62,65,66}$ Most studies (21) were undertaken in European countries, and 52\% (14) were prospective trials. Regarding the clinical setting, 10 studies were undertaken in private clinics, seven in faculty clinics, five in public dental health facilities, one in a dental school, one in the dental clinic of a defense agency, and two in more than one type of clinical facility. The quality/failure of restorations was

\footnotetext{
* References 15, 16, 19, 42, 45-50, 56, 60, 62-67.

$\dagger$ References 15, 16, 19, 37, 42, 44-50, 53, 54, 65, 67-70.

$\ddagger$ References 15, 37, 45, 46, 48, 50, 54, 61, 63, 67.
}

assessed with the criteria for the clinical evaluation of dental restorative materials for use by the United States Public Health Service (USPHS), or modified USPHS (11), the standards of quality of dental care used by the Californian Dental Association (1), clinical history extracted from patients' files (5), other predefined clinical criteria (4), and the association of methods (6), for example, by using the Fédération Dentaire Internacionale clinical criteria for the evaluation of restorations and the clinical history. The restorations were placed in both premolar and molar teeth in most of the investigations (23), filling small, moderate, and extensive cavities. One study included practically only premolar teeth (98\%), ${ }^{48}$ and three others included exclusively molars (Table 2). ${ }^{37,68,69}$

The follow-up times are presented in Tables 2 and 3. The first refers to the maximum period to which restorations were followed, and in Table 3 , the follow-up is given according to the period used in the survival analysis (survival\%; AFR\%) in the original article or the period was selected by the authors of this review, taking into account the number of restorations remaining in life tables in one case. ${ }^{53}$

Regarding the size of the studies (Table 3), two were large prospective trials undertaken in public dental health centers, with high numbers of patients $\left(1873^{45}\right.$ and $\left.2881^{48}\right)$, restorations $\left(3286^{45}\right.$ and $\left.4355^{48}\right)$, and operators $\left(27^{45}\right.$ and $115^{48}$ ) involved. The dropout of patients ranged from $0^{49}$ up to $41 \%,{ }^{42}$ and in most prospective studies, dropouts varied between 8 and $22 \% .^{34,46,54,58,61,62,64,65}$ Concerning the age group of the participating patients, several studies (21) had a wide age range. The studies of Roberts and Sherriff (1990), ${ }^{69}$ Soncini and others (2007), ${ }^{49}$ and Pallesen and others $(2013)^{48}$ included only children ${ }^{49}$ or children and adolescents. ${ }^{48,69}$

Effect-Regarding the statistical method in the studies, information was retrieved concerning the use of univariate or multivariate data analysis (Table 4). Statistical significance of all investigated variables (yes/no) in each study is shown in Table 4. The size of the effect (odds ratio/hazard ratio) for patient-related variables is displayed in Table 5 from available studies.

Sixteen studies included the patient age or age range in the analysis, which was found to be significant in $47 \%$ (seven) of the studies. ${ }^{42,45,48,50,53,67,68}$ Pallesen and others $(2013)^{48}$ investigated several variables influencing the survival of class I and II composite restorations in a 


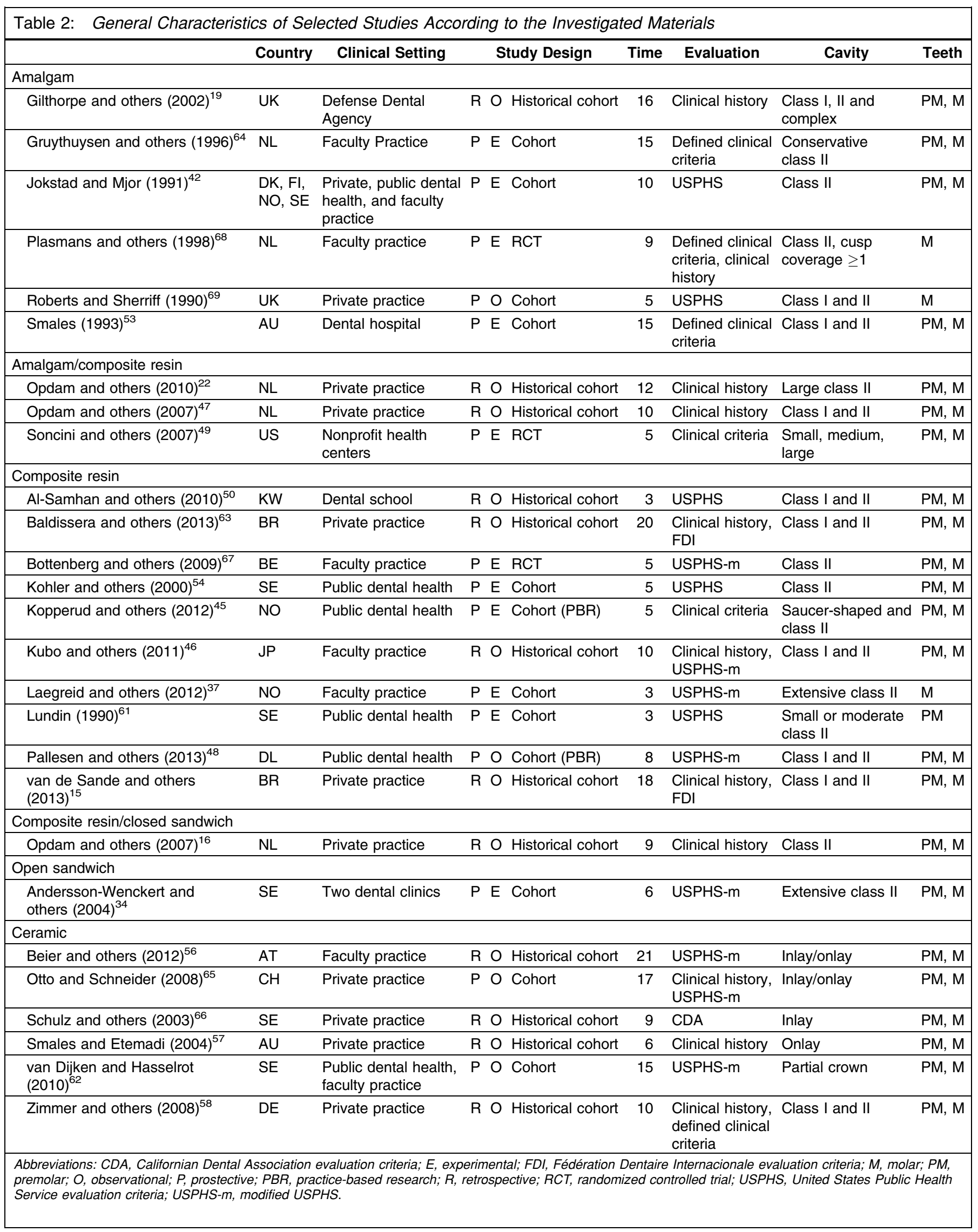


Table 3: Information Regarding the Size of Selected Studies, Patients' Age, Survival (\%), and Annual Failure Rate (AFR\%)

\begin{tabular}{|c|c|c|c|c|c|c|c|c|c|c|}
\hline & $\begin{array}{l}\text { Patients } \\
\text { (P) }\end{array}$ & $\begin{array}{c}\mathbf{P} \\
\text { Dropout, } \\
\%\end{array}$ & $\begin{array}{l}\text { P Age } \\
\text { Range }\end{array}$ & $\begin{array}{c}\text { P } \\
\text { Mean } \\
\text { Age, y }\end{array}$ & $\begin{array}{c}\text { Restorations } \\
\text { (R) }\end{array}$ & $\begin{array}{c}R \text { at } \\
\text { Last } \\
\text { Recall }\end{array}$ & Operators & Time $^{b}$ & $\begin{array}{c}\text { Survival, } \\
\%\end{array}$ & AFR\% \\
\hline \multicolumn{11}{|l|}{ Amalgam } \\
\hline Gruythuysen and others (1996) ${ }^{64}$ & 183 & 21 & $15-40$ & 23 & 1529 & 1213 & 3 & 15 & $\underline{82}$ & $\underline{1.3}$ \\
\hline Jokstad and Mjor (1991) ${ }^{42}$ & 210 & 41 & 8-71 & 28 & 468 & 256 & 7 & 10 & 81 & 2.1 \\
\hline Smales $(1993)^{53 c}$ & $105^{d}$ & - & $<20->41$ & - & 582 & - & 1 & 5 & $\underline{95}$ & $\underline{1.0}$ \\
\hline \multicolumn{11}{|l|}{ Amalgam ${ }^{\mathrm{A}} /$ Composite resin ${ }^{\mathrm{CR}}$} \\
\hline Opdam and others $(2010)^{22}$ & 273 & NA & $22-77$ & 48 & 1949 & NA & 1 & 12 & $75^{\mathrm{A}} ; 81^{\mathrm{CR}}$ & $1.7^{\mathrm{CR}} ; 2.4^{\mathrm{A}}$ \\
\hline Opdam and others $(2007)^{47}$ & 621 & NA & - & - & 2867 & NA & 2 & 10 & $79^{\mathrm{A}} ; 82^{\mathrm{CR}}$ & $1.9^{\mathrm{CR}} ; 2.3^{\mathrm{A}}$ \\
\hline Soncini and others $(2007)^{49 c}$ & 399 & 0 & $6-10$ & 8 & 1262 & 1262 & 6 & 5 & $\underline{85^{\mathrm{CR}} ; 89^{\mathrm{A}}}$ & $2.3^{\mathrm{A}} ; 3.2^{\mathrm{CR}}$ \\
\hline Bottenberg and others (2009) ${ }^{67}$ & 32 & 27 & $19-56$ & 38 & 132 & 77 & 3 & 5 & $\underline{81}$ & $\underline{4.1}$ \\
\hline Kohler and others $(2000)^{54}$ & 45 & 8 & $11-63$ & 26 & 63 & 51 & 3 & 5 & 72 & $\underline{6.3}$ \\
\hline Kopperud and others $(2012)^{45 e}$ & 1873 & 29 & $6-57$ & 15 & 3286 & 2396 & 27 & 5 & $\underline{88}$ & 2.9 \\
\hline Kubo and others $(2011)^{46 f}$ & 77 & 9 & $8-82$ & 57 & 170 & 155 & 1 & 10 & $58 ; 90$ & $1.1 ; 5.2$ \\
\hline Laegreid and others $(2012)^{37}$ & 74 & 1 & $31-80$ & 50 & 74 & 73 & 2 & 3 & 88 & 4.2 \\
\hline Lundin $(1990)^{61}$ & 213 & 12 & $14-75$ & 33 & 242 & 214 & 24 & 3 & 93 & $\underline{2.2}$ \\
\hline Pallesen and others $(2013)^{48}$ & 2881 & - & $5-18$ & 14 & 4355 & - & 115 & 8 & 84 & 2.0 \\
\hline $\begin{array}{l}\text { van de Sande and others } \\
(2013)^{15}\end{array}$ & 44 & NA & $25-71$ & 47 & 306 & NA & 1 & 15 & 70 & 2.3 \\
\hline \multicolumn{11}{|l|}{ Composite resin ${ }^{C R} /$ Sandwich ${ }^{S}$} \\
\hline Schulz and others $(2003)^{66}$ & 52 & 2 & $28-79$ & 54 & 109 & 107 & 1 & 7 & 85 & $\underline{2.3}$ \\
\hline Smales and Etemadi $(2004)^{57}$ & 50 & NA & $15->51$ & - & 97 & NA & 2 & 6 & $61 ; 62$ & $6.3 ; 6.7$ \\
\hline $\begin{array}{l}\text { van Dijken and Hasselrot } \\
(2010)^{62 c}\end{array}$ & $121^{d}$ & 10 & $26-81$ & 52 & 117 & - & 4 & 15 & $\underline{66 ; 82}$ & $1.3 ; 2.8$ \\
\hline Zimmer and others $(2008)^{58}$ & 95 & 22 & $22-65$ & 44 & 308 & 226 & 1 & 10 & 86 & 1.4 \\
\hline \multicolumn{11}{|c|}{ 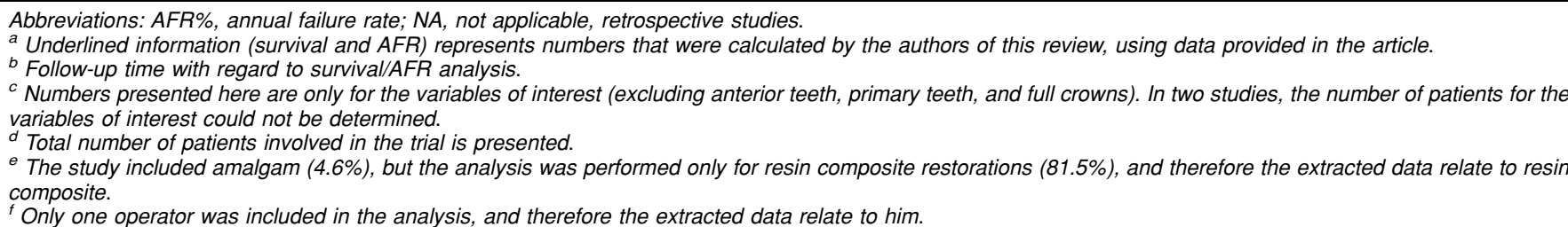 } \\
\hline
\end{tabular}

large sample of children/adolescents. The study reported that among the patient-related factors, only the age range influenced the results, with adolescents showing a hazard ratio of 0.43 compared with younger children (5-11 years; Tables 4 and 5$).{ }^{48} \mathrm{Also}$, in Kopperud and others (2012), ${ }^{45}$ younger patients at baseline influenced negatively the survival of composite restorations. When age was categorized into over/under 30 years, no effect on composite restoration survival was found in van de Sande and others 
$(2013),{ }^{15}$ but lower survival rates for amalgam restorations were observed for patients older than 30 years in Plasmans and others (1998). ${ }^{68}$ Two studies also reported lower survival rates in patients older than $41^{53}$ and 45 years ${ }^{50}$ when compared with other age groups. In this last study, the hazard ratios for patients younger than 15 years and older than 45 years were not significantly different. ${ }^{50}$

Regarding gender, $23.5 \%$ (four of 17) reports found a significant effect on survival, showing more failures for men in three studies ${ }^{37,62,64}$ and for women in one. ${ }^{50}$

The caries risk profile or related variables (DMFT, number of restorations, and caries severity or activity) was present in the analysis of 15 studies, and a significant effect on survival was reported for high-caries-risk individuals (or related variables) in $66.7 \%$ (10) of these studies. ${ }^{\S}$ These studies included amalgam, ${ }^{19,22,42,47,49}$ resin composite ${ }^{15,22,45,47-49,54}$ and sandwich ${ }^{16,34}$ restorations. For individuals classified as having high caries risk, the hazard ratio ranged from 2.45 to 4.40 compared with low-risk individuals. ${ }^{15,16,34}$ Kubo and others $(2011)^{46}$ evaluated the retreatment risk and did not find a significant effect on survival for class I and II composite restorations. In the study by Kopperud and others (2012), ${ }^{45}$ no effect of caries severity on survival of class II composite restorations was found, but a higher DMFT score was significantly related to lower restoration survival. The study by Laegreid and others (2012), ${ }^{37}$ in which the Cariogram Program was used to estimate the caries risk, reported no effect on survival of extensive composite restorations according to different risk profiles. Also, Lundin $(1990)^{61}$ reported that no correlation was found when caries experience (DFT) and failure rates were compared between different composites.

The effect of bruxism or parafunctional habits was significant in three of six reports in which this factor was investigated. Studies reporting a significant effect included amalgam, ${ }^{53}$ resin composite,${ }^{15}$ and partial-crown ceramic restorations. ${ }^{62}$ Patients presenting high caries risk and bruxism were found to present a hazard ratio of 8.31 compared with lowrisk patients in van de Sande and others (2013). ${ }^{15}$ The other three studies reported no effect of this variable on survival of inlay/onlay ceramic restorations. ${ }^{56,57,62}$

Bottenberg and others (2009) ${ }^{67}$ analyzed the patient as a factor and found a significant contribution of this variable on general failures of composite

$\S$ References 15, 16, 19, 22, 25, 38, 47, 49, 51, 53. restorations. Patient oral hygiene had a significant effect on survival of composite restorations in the study of Al-Samhan and others (2010), ${ }^{50}$ but the effect of this variable was not significant in the study of Kopperud and others (2012), ${ }^{45}$ and neither was oral health significant in the survival of amalgam restorations, as reported by Smales (1993). ${ }^{53}$

\section{DISCUSSION}

The survival of restorations may be affected by a number of variables, and therefore, the inclusion of known factors as well as potential factors into analysis is crucial to determine treatment alternatives and prognosis, according to specific conditions at the tooth level and patients' needs at an individual level. As seen by the dates of the included studies, 10 were published from 2010 on and 11 between 2002 and 2009. So even though previous studies $^{42,53,61,64,68,69}$ had reported an influence of patient factors in the survival of restorations, increased attention in research took longer to take place. Yet, as seen in the results of this review, it became clear that there is a lack of standardized methods to assess patient-related factors. Even in studies in which these factors were investigated, there was no uniformity on clinical parameters used, and the description of cutoff points was frequently missing or vague. This is likely due to the difficulty of establishing the relationship between etiological factors and clinical signs and the diagnosis for several conditions in the dental field. Since several factors were addressed in the studies, each holding its own particularities, the discussion is presented under topics, as follows.

\section{Caries}

In the caries disease process, multiple risk indicators/ predictors may be needed to establish a graded risk status and future caries prediction. ${ }^{71}$ Certainly, the collection of several variables is important to correctly identify risk indicators in each patient, guiding preventive and treatment strategies at the individual level. ${ }^{72}$ Nonetheless, when investigating restoration survival, the use of simplified measures may provide a good estimate of the disease activity when the restoration is placed and in follow-up evaluations. Visible cavitation or caries into dentin identified by radiographic examination was shown to significantly correlate with several caries risk factors. ${ }^{73}$ Caries lesions leading to restorations within a three-year period was one of the correlated items, ${ }^{73}$ which is similar to the criteria applied in some of the included studies reporting a significant influence on restora- 
Table 4: Statistical Significance $\left(\mathrm{Yes}^{+} / \mathrm{No}^{-}\right.$) of the Investigated Variables on Restoration Survival and the Statistical Method Applied (ie, Univariate [U] or Multivariate [M] Analysis) ${ }^{a}$

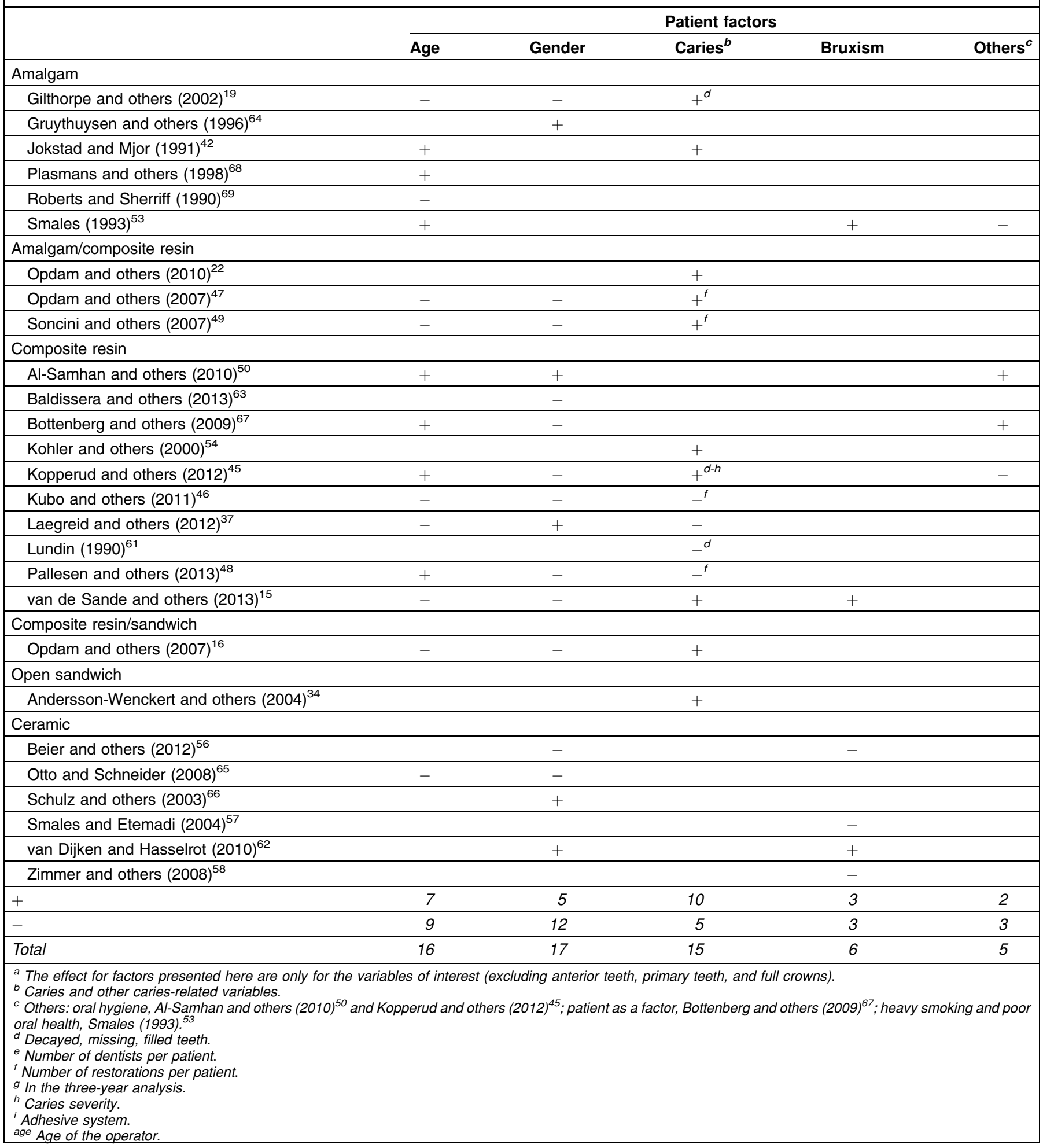


Table 4: Statistical Significance $\left(\mathrm{Yes}^{+} / \mathrm{No}^{-}\right)$of the Investigated Variables on Restoration Survival and the Statistical Method Applied (ie, Univariate [U] or Multivariate [M] Analysis) ${ }^{a}$ (ext.)

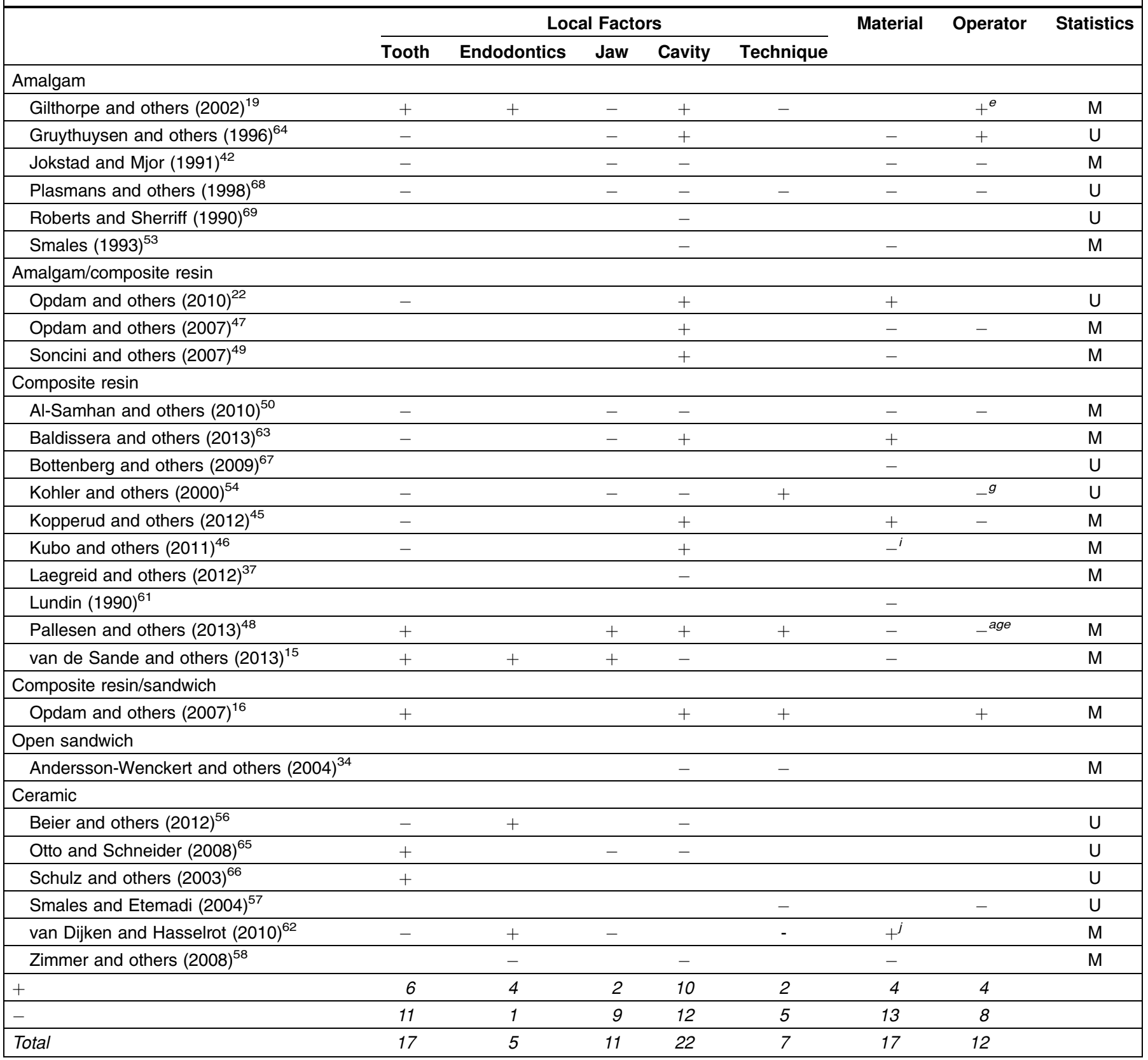

tion survival. ${ }^{15,22,42}$ Although the included studies reported different methods and cutoff points (Table 1 ), most of them were able to show an influence of caries-related variables on restoration failure (Table 4). Decayed, missing, filled teeth-surfaces (DMFT-S), representing past caries experience, has been used as a predictor variable and has shown that higher caries experience in the past correlates with caries increment. ${ }^{74}$ Also, individuals presenting a higher level of caries disease (component $\mathrm{D}$ from the DMFT index) at the age 15 were more likely to have failed restorations when they were 24 years old. ${ }^{75}$ Three of the included studies have used DMFT/DFT, and two reported a significant effect on restoration survival. ${ }^{19,45}$ The other study reported that no correlation was found for DFT and failure rates, but the statistical method was not described in the article. In addition, most of the patients were dental students, which could have influenced the results. ${ }^{61}$ For studies on restoration survival, the use of cumulative scores as a single 


\begin{tabular}{|c|c|c|c|c|}
\hline & Factor & HR/OR & $95 \% \mathrm{Cl}$ & $\boldsymbol{P}$ \\
\hline & Age, y & & & \\
\hline \multirow{2}{*}{ Al-Samhan and others $(2010)^{50}$} & $16-30(\geq 45)$ & 0.444 & $0.225-0.877$ & 0.019 \\
\hline & $31-45(\geq 45)$ & 0.408 & $0.173-0.963$ & 0.041 \\
\hline Gilthorpe and others (2002) ${ }^{19}$ & Years & 0.99 & $0.98-1.00$ & 0.072 \\
\hline Kopperud and others $(2012)^{45}$ & $20-57(13-19)$ & 0.05 & $0.01-0.40$ & $<0.01$ \\
\hline Pallesen and others $(2013)^{48}$ & $12-19(5-11)$ & 0.43 & $0.36-0.52$ & $<0.0001$ \\
\hline \multirow[t]{2}{*}{ van de Sande and others $(2013)^{15}$} & $\geq 31(\leq 30)$ & 0.97 & $0.54-1.75$ & 0.938 \\
\hline & Gender & & & \\
\hline Al-Samhan and others $(2010)^{50}$ & $\mathrm{~F}(\mathrm{M})$ & 2.982 & $1.178-7.540$ & 0.021 \\
\hline Laegreid and others $(2012)^{37}$ & $M(F)$ & 8.7 & - & 0.022 \\
\hline Pallesen and others $(2013)^{48}$ & $\mathrm{M}(\mathrm{F})$ & 0.92 & $0.75-1.12$ & 0.40 \\
\hline van de Sande and others $(2013)^{15}$ & $F(M)$ & 1.35 & $0.72-2.53$ & 0.347 \\
\hline \multirow[t]{2}{*}{ van Dijken and Hasselrot $(2010)^{62}$} & $M(F)$ & 1.959 & $1.00-3.84$ & 0.050 \\
\hline & Oral hygiene & & & \\
\hline Al-Samhan and others $(2010)^{50}$ & Poor (good) & 9.046 & $1.021-19.751$ & 0.014 \\
\hline \multirow[t]{2}{*}{ Kopperud and others $(2012)^{45}$} & Medium/poor (good) & 1.31 & $0.90-1.90$ & 0.15 \\
\hline & Caries risk & & & \\
\hline Andersson-Wenckert and others $(2004)^{34}$ & High (low) & 2.85 & $1.35-6.02$ & 0.001 \\
\hline Opdam and others $(2007)^{16}$ & High (low) & 2.45 & $1.55-3.88$ & $<0.001$ \\
\hline Kopperud and others $(2012)^{45}$ & Restorations & & & \\
\hline Opdam and others $(2007)^{47}$ & Number of restorations & $0.91^{a}$ & $0.86-0.95$ & $<0.001$ \\
\hline \multirow[t]{2}{*}{ Pallesen and others $(2013)^{48}$} & $1(\geq 2)$ & 0.94 & $0.78-1.13$ & 0.51 \\
\hline & Bruxism & & & \\
\hline van de Sande and others $(2013)^{15}$ & Yes (no) & 2.78 & $1.39-5.59$ & $<0.001$ \\
\hline van Dijken and Hasselrot $(2010)^{62}$ & No (yes) & 0.38 & $0.19-0.77$ & 0.007 \\
\hline van de Sande and others $(2013)^{15}$ & High caries risk and bruxism (no risk) & 8.31 & $4.40-15.66$ & $<0.001$ \\
\hline
\end{tabular}

indicator may overestimate the caries risk. The increment in DMFS/DFS on a given interval of time should also be given, because it would be comparable to new restorations and cavitated lesions as reported in other studies.

Identifying high-caries-risk patients when the restoration is placed may provide a good estimate of individuals at higher risk of restoration failure. ${ }^{76}$
A large retrospective cohort study, with seven years of follow-up, showed that high-caries-risk patients developed more primary dentin lesions as well as secondary caries compared with patients classified as no/low risk at baseline. At baseline, the most marked differences between these groups were the number of dentin lesions ( 0.45 for low risk vs 3.1 for high risk) and secondary caries ( 0.07 for low risk vs 1.0 for high risk). ${ }^{74}$ 
Oral health and oral hygiene were evaluated in three studies, ${ }^{45,53,50}$ and one reported a significant contribution of this variable in restoration survival. ${ }^{50}$ Although individuals presenting a high level of biofilm accumulation throughout life may be more prone to oral health problems in adult life, as reported in a birth cohort study, ${ }^{77}$ other variables should be jointly evaluated when investigating restoration survival. Still, the observation of biofilm accumulation and gingival bleeding indexes during the follow-up of patients is essential to observe their compliance to treatment.

Another variable investigated in the studies and included in the present review was the number of restorations per patient (regardless of the reason for placement) at a given period of time. Individuals with more restorations were shown to experience more failures than individuals with fewer restorations in two reports, ${ }^{47,49}$ but this variable was not significantly related with restoration survival in two other studies. ${ }^{46,48}$ In this sense, considering all the above-mentioned reasoning, registering the number of cavitated caries lesions, dentin caries from radiographic evaluations, or interventions due to caries within a two- to three-year period seems a straightforward method to identify patients at high risk. $^{72}$

\section{Bruxism and Occlusal Loading}

The general mechanisms-friction, corrosion, and stress $^{78}$ - that can affect sound tooth structures in the form of noncarious tooth surface lesions may also affect restorations. Tooth wear and bruxism are multifactorial conditions, sometimes overlapping each other because mixed mechanisms may be involved. ${ }^{79}$ For both, physiologic and pathologic distinctions should be identified, since bruxism habits may be seen as a normal activity, ${ }^{80,81}$ and tooth wear is part of a normal physiologic process. ${ }^{82,83}$ The assessment of these conditions usually takes into account objective clinical evaluation and subjective self-reported information. ${ }^{83,84}$

Most of the studies included in the present review, assessing bruxism, have not objectively stated the cutoff points applied to determine the condition. Thus, a direct comparison of methods is not feasible. Among the studies evaluating ceramics, no significant effect on the failure rates for inlay/onlay restorations was found.$^{56-58}$ However, for extensive partial crowns, a significant effect for bruxism was shown in restoration survival. ${ }^{62}$ Regarding other materials, only two studies have investigated the effect of bruxism, and in both cases, this variable significantly influenced the survival of amalgam ${ }^{53}$ and composite ${ }^{15}$ restorations. Other reports were found presenting information regarding bruxism behavior only in the discussion of the results, where more failures were seen in bruxing patients. ${ }^{41,59,65}$

A review on bruxism prevalence in adults showed that several flaws in the studies were related to the lack of valid criteria to diagnose this condition. ${ }^{85} \mathrm{~A}$ grading system was proposed by Lobbezoo and others $(2013)^{86}$ in which bruxism should be registered as "possible," "probable," or "definite." These distinctions should be made according to the assessment strategy, namely, solely by means of self-report information with questionnaires (possible), by the use of questionnaires and clinical evaluation (probable), and, for a definite diagnosis, by the use of both preceding evaluations plus an electromyographic recording (awake bruxism) or polysomnography (sleep bruxism). ${ }^{86}$ These distinctions seem useful for the awareness of clinicians and researchers that bruxism may be under- or overestimated, especially when only one method is applied. ${ }^{87}$ In addition to this grading system, the severity of bruxism should be part of the assessments. ${ }^{85}$ Questionnaires designed with this purpose should include response options other than simply "yes" or "no," such as proposed by Liu and others $(2014)^{88}$ for tooth wear assessment, in which "mostly," "sometimes," and "never" were included. As a fourth response option, "not aware" could also be added. For the clinical evaluation, specifically concerning the intraoral examination, indexes should be used to grade the severity of clinical signs.

In addition, little is known about the effect of high occlusal loads and stress concentration on tooth surface loss and on restorations, except that several mechanisms may be involved. ${ }^{79}$ In vitro studies on occlusal load frequently focus on abfraction on premolar teeth, and stress concentration in the cervical area was shown to slightly increase when an occlusal restoration is present. ${ }^{89}$ Probably the cavity configuration as well as the axis and force of applied loads will generate distinct stresses on different teeth. Material properties, ${ }^{90}$ the occlusal load, and the cavity type ${ }^{91}$ were shown to influence stress concentration patterns. This might be particularly relevant for restorations placed in patients presenting high occlusal stress risk, due to bruxism, parafunctional habits, heavy occlusal loading, or severe tooth wear. Hence, for practical reasons, the measurement of clinical signs regardless of the name of the condition seems advisable when investigating restoration survival. 
Ideally, assessment strategies developed with this purpose should be appropriate for use in research trials but specially by practicing dentists.Factors taking long periods to influence restoration survival are probably more suitable for practice-based research in which patients are usually not particularly selected, as seen in several of the studies included in the present review. With time, moderate to severe conditions will be identified by the patient and/or the clinician during routine dental appointments and should be clearly distinguished in clinical files. For example, the degree of attrition of the tooth structure as reported by Felden and others $(2000)^{59}$ may serve to measure tooth structure loss regardless of the etiological factor(s).

\section{Gender and Age}

Few studies have found a significant influence of gender on survival of restorations, and this variable is probably related to others. Men, in general, may have stronger bite forces than women, ${ }^{92}$ which could contribute to more failures due to fatigue of the material or bonding interfaces, leading to fracture and debonding and increased failure rates. As discussed by Schulz and others (2003), ${ }^{66}$ the combination of a patient effect, such as unfavorable loading, and an inadequate material dimension may have contributed to a higher failure rate in men observed in their study. The presence of bruxism and parafunctional habits may overcome the influence of gender, and therefore gender should not be an isolated variable when evaluating restoration survival. In addition, women are more concerned with their health and they attend dental services more regularly. ${ }^{93}$ Such an aspect is important because it has been demonstrated that individuals having regular dentist visitations during the life course may exhibit better oral health outcomes. ${ }^{94}$

The same line of reasoning may be valid when considering the influence of age on restoration survival. Other factors, such as caries risk in younger individuals ${ }^{42}$ or more complex restorations and greater tooth structure loss after several restorative interventions in older individuals, may superimpose the effect of age. Pallesen and others $(2013)^{48}$ observed, among children and adolescents, a higher intervention rate for younger individuals at baseline. The authors discussed that findings could be related to differences in caries risk and the more difficult cooperation of younger children during treatment procedures. So although age may present a significant effect, polarized for the very young and more mature patients, ${ }^{45,48,50}$ the analysis of the contribution of age on restoration survival, as it is for gender, should not be seen under an isolated perspective.

\section{Other Patient-Related Variables}

Socioeconomic status and educational level may also influence restoration survival, ${ }^{75}$ but no longitudinal evaluations investigating the effect of socioeconomic vulnerability were found. Although Soncini and others $(2007)^{49}$ characterized the participants according to ethnicity, household income, and educational level of the caregiver, this information was used primarily to verify the equal distribution of the materials (amalgam and resin composite) for each of the displayed characteristics. It is also mentioned that the statistical model was adjusted for some patient factors if they were statistically significant or changed the effect (10\% or more) of the restoration material. Since for permanent teeth, the model was adjusted only for number of restorations in the mouth, the other factors (age, sex, and socioeconomic status) presumably did not influence restoration survival. However, the collection and reporting of these data are of importance because they provide the characterization of the sample population. In fact, when evaluating the survival of restorations in specialized private practices, a more favorable environment may be displayed because patients with a higher socioeconomic background usually attend these facilities, ${ }^{63,95}$ especially considering countries where the dental health system does not rely on public coverage. ${ }^{96}$ Thus, a better general and oral health may be expected, with lower chance of failure, and restoration survival may be overestimated for the general population, where individuals with different economic backgrounds are included. ${ }^{10}$

\section{Statistical Analysis}

One important point to be raised when investigating patient risk factors for longevity of restorations is the use of appropriate statistical analysis. Generally, a descriptive analysis of interest variables is recommended, followed by the analysis of associations between each evaluated patient factor and failure of restorations, often called univariate analysis. From the 27 selected studies, 10 have analyzed factors associated with longevity of restorations only in a univariate way (Table 4). This strategy does not consider the complex interrelationships that exist between all covariates investigated. For example, it is well established in the literature that dental caries is a multifactorial condition, affected by socioeconomic, behavioral, and tooth factors, among others. 
In this way, to investigate the real effect of caries on longevity of restorations, it is strongly recommended to adjust its effect by other variables that are associated with both caries and longevity of restorations, which can act as confounders of this association, using multivariate methods. An increasing tendency to improve the quality of the analysis using multivariate models is observed among included studies. Another aspect that requires attention when patient factors are investigated is data organization. Most of articles on longevity of restorations considered that all variables are at the same level of organization, ignoring the complex nature of dental studies, where variables from surfaces/teeth/ patients are analyzed together. Generally, more than one restoration is evaluated per patient. In this case, the assumption of independence between observations (restorations) leads to errors in data analysis and interpretation of results. Restorations are clustered within patients. This means that an important correlation exists between restorations of the same patient. The use of methods that ignore this correlation may lead to incorrect results, increasing the probability of rejection of the null hypothesis (ie, finding statistically significant results when none are present in the data). ${ }^{97}$ This problem is present in most of articles that use a survival analysis approach, by conventional Cox regression models. To deal with data organization, multilevel models are the appropriate method that adjusts the results by correlation existing between restorations from the same patient. ${ }^{75}$ Recent studies on longevity of restorations have used Cox regression models with shared frailty to investigate patient risk factors. ${ }^{15,63}$ These models for survival analysis are analogous to multilevel regression models with random effects and consider the intragroup correlation being recommended for future studies.

\section{Final Considerations}

The selection of patients for particular treatment alternatives is often restricted to certain risk profiles. Recommendations for restorative techniques according to patient-related conditions are made, regardless of sound evidence to support the clinical decision. ${ }^{98}$ Interestingly, the methods used to estimate the risk, meaning the criteria applied for patient inclusion/exclusion, are frequently missing, and the description for patient exclusion is often limited to "poor oral hygiene" or "patients with bruxism were excluded." While in retrospective evaluations, investigators may be limited to work with information available in the clinical records, in prospective studies, the characterization of the sample population (by means of indexes, self-reported information, and cutoff points) should be far more complete and available for the reader, even if data will be presented only descriptively. A recent report reinforced the need to use guidelines when reporting clinical studies, to increase the completeness and transparency of biomedical research. Inadequate reporting of research may lead to wasted research resources, increasing the risk for publication inaccuracy or biased data, with implications for health care decisions. $^{99}$

A survey among general dentists in Kuwait showed that the dentist's choice regarding direct restorative materials is influenced by factors such as oral hygiene, numbers of restorations in the mouth, and cavity size. ${ }^{2}$ However, no strong evidence exists to support the use of a particular material for either situation. ${ }^{100}$ Material choice seems to be related to dentists' preference, country, and cultural trends. ${ }^{5,101-104}$ Future investigations should deal with individuals' particularities and risk factors, assisting the clinical decision making for materials and techniques in challenging situations.

It is noteworthy that studies evaluating the survival of restorations have been mostly focused on the comparison between materials, including a very restricted group of patients. Aiming for studies more easily translated to daily clinical practice, investigations including patients with different socioeconomic and education backgrounds, with different levels of caries and occlusal stress, should be encouraged. Another interesting approach would be to set new prospective studies on longevity of dental restorations recruiting only volunteers/patients at high risk, considering that these risk situations would be the utmost challenge for the restorations. Also, since the events experienced during the life course may affect a series of oral health outcomes in other periods of life, ${ }^{105}$ they should be considered during the design and evaluation of studies reporting the longevity of posterior restorations. Considerable time in clinical practice is spent on replacing failed restorations, ${ }^{106}$ with a high cost for the individuals and for health systems. ${ }^{107,108}$ Restorations are replaced/repaired, and in the near future, they tend to fail again, ${ }^{109,110}$ because the dentist is treating the consequences instead of the causes for failures. ${ }^{74}$ Therefore, the investigation of factors related to patients is crucial to change their current status, increase the survival of restorative procedures, and cut costs. 


\section{CONCLUSIONS}

Within the limits of the information collected in the current review, some conclusions and recommendations can be made:

1. The assessment of patient factors along with other variables should become part of clinical studies investigating restoration survival, since several of these factors were shown to influence the failure of restorations, regardless of the material type.

2. Several studies lacked detailed information regarding the method used to classify patients. A full description should be clearly stated together with the cutoff points applied, so the sample population from different studies can be compared. More importantly, with the characterization of population, results from clinical studies may be interpreted according to individual particularities and not only in relation to materials and cavity variables.

3. For caries risk assessment, simplified methods based in caries activity were presented and seem appropriate for use in restoration survival analysis. The collection of this information is available in periodic radiographic examinations and in clinical files where the reason for intervention is registered. The higher hazard ratio found for restoration failure in caries-active individuals may assist the clinician to inform their patients toward adherence to treatment.

4. Few studies were found investigating the role of bruxism/parafunctional habits on restoration survival, and different results were reported. Improvement in methods for the assessment of patients under high occlusal stress risk is needed. The association of self-reported information and clinical indexes is encouraged, and the severity of the condition should be distinguished objectively.

5. For data analysis, multivariate models should be used, and when available, several restorations should be included per patient, since risk factors related to the individual may be masked when only one restoration is selected.

\section{Regulatory Statement}

This study was conducted in accordance with all the provisions of the human subjects oversight committee guidelines and policies of Federal University of Pelotas in Brazil.

\section{Conflict of Interest}

The authors have no proprietary, financial or other personal interest of any nature or kind in any product, service and/or company that is presented in this article.
(Accepted 1 May 2015)

\section{REFERENCES}

1. Marcenes W, Kassebaum NJ, Bernabe E, Flaxman A, Naghavi M, Lopez A, \& Murray CJ (2013) Global burden of oral conditions in 1990-2010: a systematic analysis Journal of Dental Research 92(7) 592-597.

2. Khalaf ME, Alomari QD, \& Omar R (2014) Factors relating to usage patterns of amalgam and resin composite for posterior restorations-a prospective analysis Journal of Dentistry 42(7) 785-792.

3. Correa MB, Peres MA, Peres KG, Horta BL, Barros AD, \& Demarco FF (2012) Amalgam or composite resin? Factors influencing the choice of restorative material Journal of Dentistry 40(9) 703-710.

4. Laegreid T, Gjerdet N, Johansson A, \& Johansson AK (2014) Clinical decision making on extensive molar restorations Operative Dentistry 39(6) E231-E240.

5. Nascimento GG, Correa MB, Opdam N, \& Demarco FF (2013) Do clinical experience time and postgraduate training influence the choice of materials for posterior restorations? Results of a survey with Brazilian general dentists Brazilian Dental Journal 24(6) 642-646.

6. Hurst D (2010) Indirect or direct restorations for heavily restored posterior adult teeth? Evidence-Based Dentistry 11(4) 116-117.

7. Palaniappan S, Bharadwaj D, Mattar DL, Peumans M, Van Meerbeek B, \& Lambrechts P (2009) Three-year randomized clinical trial to evaluate the clinical performance and wear of a nanocomposite versus a hybrid composite Dental Materials 25(11) 1302-1314.

8. Shi L, Wang X, Zhao Q, Zhang Y, Zhang L, Ren Y, \& Chen Z (2010) Evaluation of packable and conventional hybrid resin composites in Class I restorations: threeyear results of a randomized, double-blind and controlled clinical trial Operative Dentistry 35(1) 11-19.

9. Yazici AR, Ustunkol I, Ozgunaltay G, \& Dayangac B (2014) Three-year clinical evaluation of different restorative resins in class I restorations Operative Dentistry 39(3) 248-255.

10. Demarco FF, Corrêa MB, Cenci MS, Moraes RR, \& Opdam NJM (2012) Longevity of posterior composite restorations: not only a matter of materials Dental Materials 28(1) 87-101.

11. Klink A, \& Huettig F (2013) Complication and survival of Mark II restorations: 4-year clinical follow-up International Journal of Prosthodontics 26(3) 272-276.

12. Collins CJ, Bryant RW, \& Hodge KL (1998) A clinical evaluation of posterior composite resin restorations: 8year findings Journal of Dentistry 26(4) 311-317.

13. van Dijken JW (2000) Direct resin composite inlays/ onlays: an 11 year follow-up Journal of Dentistry 28(5) 299-306.

14. Akerboom HB, Advokaat JG, Van Amerongen WE, \& Borgmeijer PJ (1993) Long-term evaluation and rerestoration of amalgam restorations Community Dentistry and Oral Epidemiology 21(1) 45-48. 
15. van de Sande FH, Opdam NJ, Rodolpho PA, Correa MB, Demarco FF, \& Cenci MS (2013) Patient risk factors' influence on survival of posterior composites Journal of Dental Research 92(Supplement 7) 78s-83s.

16. Opdam NJ, Bronkhorst EM, Roeters JM, \& Loomans BA (2007) Longevity and reasons for failure of sandwich and total-etch posterior composite resin restorations Journal of Adhesive Dentistry 9(5) 469-475.

17. Monaco C, Caldari M, Scotti R, \& Group ACR (2013) Clinical evaluation of 1,132 zirconia-based single crowns: a retrospective cohort study from the AIOP clinical research group International Journal of Prosthodontics 26(5) 435-442.

18. Beier US, Kapferer I, \& Dumfahrt H (2012) Clinical long-term evaluation and failure characteristics of 1,335 all-ceramic restorations International Journal of Prosthodontics 25(1) 70-78.

19. Gilthorpe MS, Mayhew MT, \& Bulman JS (2002) Multilevel survival analysis of amalgam restorations amongst RAF personnel Community Dental Health 19(1) 3-11.

20. Kolker JL, Damiano PC, Caplan DJ, Armstrong SR, Dawson DV, Jones MP, Flach SD, Warren JJ, \& Kuthy RA (2005) Teeth with large amalgam restorations and crowns: Factors affecting the receipt of subsequent treatment after 10 years Journal of the American Dental Association 136(6) 738-748.

21. Nicolaisen S, Von Der Fehr FR, Lunder N, \& Thomsen I (2000) Performance of tunnel restorations at 3-6 years Journal of Dentistry 28(6) 383-387.

22. Opdam NJ, Bronkhorst EM, Loomans BA, \& Huysmans MC (2010) 12-year survival of composite vs. amalgam restorations Journal of Dental Research 89(10) 1063-1067.

23. van Dijken JW (2003) A 6-year clinical evaluation of Class I poly-acid modified resin composite/resin composite laminate restorations cured with a twostep curing technique Dental Materials 19(5) 423-428.

24. van Dijken JW (2010) Durability of resin composite restorations in high C-factor cavities: a 12-year follow-up Journal of Dentistry 38(6) 469-474.

25. van Dijken JW, Kieri C, \& Carlen M (1999) Longevity of extensive class II open-sandwich restorations with a resin-modified glass-ionomer cement Journal of Dental Research 78(7) 1319-1325.

26. van Dijken JW, \& Lindberg A (2009) Clinical effectiveness of a low-shrinkage resin composite: a five-year evaluation Journal of Adhesive Dentistry 11(2) 143-148.

27. van Dijken JW, \& Pallesen U (2011) Clinical performance of a hybrid resin composite with and without an intermediate layer of flowable resin composite: a 7-year evaluation Dental Materials 27(2) 150-156.

28. van Dijken JW, \& Pallesen U (2013) A six-year prospective randomized study of a nano-hybrid and a conventional hybrid resin composite in Class II restorations Dental Materials 29(2) 191-198.
29. van Dijken JWV (2013) A 6-year prospective evaluation of a one-step HEMA-free self-etching adhesive in Class II restorations Dental Materials 29(11) 1116-1122.

30. van Dijken JW, \& Sunnegardh-Gronberg K (2005) A four-year clinical evaluation of a highly filled hybrid resin composite in posterior cavities Journal of Adhesive Dentistry 7(4) 343-349.

31. van Dijken JW, \& Sunnegardh-Gronberg K (2006) Fiberreinforced packable resin composites in Class II cavities Journal of Dentistry 34(10) 763-769.

32. Sjogren G, Molin M, \& van Dijken JW (2004) A 10-year prospective evaluation of CAD/CAM-manufactured (Cerec) ceramic inlays cemented with a chemically cured or dual-cured resin composite International Journal of Prosthodontics 17(2) 241-246.

33. Lindberg A, van Dijken JWV, \& Lindberg M (2007) Nine-year evaluation of a polyacid-modified resin composite/resin composite open sandwich technique in Class II cavities Journal of Dentistry 35(2) 124-129.

34. Andersson-Wenckert IE, van Dijken JW, \& Kieri C (2004) Durability of extensive Class II open-sandwich restorations with a resin-modified glass ionomer cement after 6 years American Journal of Dentistry 17(1) 43-50.

35. Van Dijken JW, \& Sunnegardh-Gronberg K (2005) A three year follow-up of posterior doxadent restorations Swedish Dental Journal 29(2) 45-51.

36. Fasbinder DJ, Dennison JB, Heys DR, \& Lampe K (2005) The clinical performance of CAD/CAM-generated composite inlays Journal of the American Dental Association 136(12) 1714-1723.

37. Laegreid T, Gjerdet NR, \& Johansson AK (2012) Extensive composite molar restorations: 3 years clinical evaluation Acta Odontologica Scandinavica 70(4) 344-352.

38. van Dijken JW (1991) A six year follow-up of three dental alloy restorations with different copper contents Swedish Dental Journal 15(6) 259-264.

39. van Dijken JW (1994) A 6-year evaluation of a direct composite resin inlay/onlay system and glass ionomer cement-composite resin sandwich restorations Acta Odontologica Scandinavica 52(6) 368-376.

40. van Dijken JW, Hoglund-Aberg C, \& Olofsson AL (1998) Fired ceramic inlays: a 6-year follow up Journal of Dentistry 26(3) 219-225.

41. Aberg CH, van Dijken JW, \& Olofsson AL (1994) Threeyear comparison of fired ceramic inlays cemented with composite resin or glass ionomer cement Acta Odontologica Scandinavica 52(3) 140-149.

42. Jokstad A, \& Mjor IA (1991) Analyses of long-term clinical behavior of class-II amalgam restorations Acta Odontologica Scandinavica 49(1) 47-63.

43. Nordbo H, Leirskar J, \& von der Fehr FR (1998) Saucershaped cavity preparations for posterior approximal resin composite restorations: observations up to 10 years Quintessence International 29(1) 5-11.

44. Suni J, Vahanikkila H, Pakkila J, Tjaderhane L, \& Larmas M (2013) Review of 36,537 patient records for 
tooth health and longevity of dental restorations Caries Research 47(4) 309-317.

45. Kopperud SE, Tveit AB, Gaarden T, Sandvik L, \& Espelid I (2012) Longevity of posterior dental restorations and reasons for failure European Journal of Oral Sciences 120(6) 539-548.

46. Kubo S, Kawasaki A, \& Hayashi Y (2011) Factors associated with the longevity of resin composite restorations Dental Materials Journal 30(3) 374-383.

47. Opdam NJ, Bronkhorst EM, Roeters JM, \& Loomans BA (2007) A retrospective clinical study on longevity of posterior composite and amalgam restorations Dental Materials 23(1) 2-8.

48. Pallesen U, van Dijken JW, Halken J, Hallonsten AL, \& Hoigaard R (2013) Longevity of posterior resin composite restorations in permanent teeth in Public Dental Health Service: a prospective 8 years follow up Journal of Dentistry 41(4) 297-306.

49. Soncini JA, Maserejian NN, Trachtenberg F, Tavares M, \& Hayes C (2007) The longevity of amalgam versus compomer/composite restorations in posterior primary and permanent teeth: findings From the New England Children's Amalgam Trial Journal of the American Dental Association 138(6) 763-772.

50. Al-Samhan A, Al-Enezi H, \& Alomari Q (2010) Clinical evaluation of posterior resin composite restorations placed by dental students of Kuwait University Medical Principles and Practice 19(4) 299-304.

51. Adolphi G, Zehnder M, Bachmann LM, \& Gohring TN (2007) Direct resin composite restorations in vital versus root-filled posterior teeth: a controlled comparative longterm follow-up Operative Dentistry 32(5) 437-442.

52. Pallesen U, \& Qvist V (2003) Composite resin fillings and inlays: an 11-year evaluation Clinical Oral Investigations 7(2) 71-79.

53. Smales RJ (1993) Rubber dam usage related to restoration quality and survival British Dental Journal 174(9) 330-333.

54. Kohler B, Rasmusson CG, \& Odman P (2000) A five-year clinical evaluation of Class II composite resin restorations Journal of Dentistry 28(2) 111-116.

55. Rasmusson CG, Kohler B, \& Odman P (1998) A 3-year clinical evaluation of two composite resins in class-II cavities Acta Odontologica Scandinavica 56(2) 70-75.

56. Beier US, Kapferer I, Burtscher D, Giesinger JM, \& Dumfahrt H (2012) Clinical performance of all-ceramic inlay and onlay restorations in posterior teeth International Journal of Prosthodontics 25(4) 395-402.

57. Smales RJ, \& Etemadi S (2004) Survival of ceramic onlays placed with and without metal reinforcement Journal of Prosthetic Dentistry 91(6) 548-553.

58. Zimmer S, Gohlich O, Ruttermann S, Lang H, Raab WH, \& Barthel CR (2008) Long-term survival of Cerec restorations: a 10-year study Operative Dentistry 33(5) 484-487.

59. Felden A, Schmalz G, \& Hiller KA (2000) Retrospective clinical study and survival analysis on partial ceramic crowns: results up to 7 years Clinical Oral Investigations 4(4) $199-205$.

60. Bratthall D, \& Hansel Petersson G (2005) Cariogram-a multifactorial risk assessment model for a multifactorial disease Community Dentistry and Oral Epidemiology 33(4) 256-264.

61. Lundin SA (1990) Studies on posterior composite resins with special reference to class II restorations Swedish Dental Journal (Supplement 73) 1-41.

62. van Dijken JW, \& Hasselrot L (2010) A prospective 15year evaluation of extensive dentin-enamel-bonded pressed ceramic coverages Dental Materials 26(9) 929-939.

63. Baldissera RA, Correa MB, Schuch HS, Collares K, Nascimento GG, Jardim PS, Moraes RR, Opdam NJ, \& Demarco FF (2013) Are there universal restorative composites for anterior and posterior teeth? Journal of Dentistry 41(11) 1027-1035.

64. Gruythuysen RJ, Kreulen CM, Tobi H, van Amerongen E, \& Akerboom HB (1996) 15-year evaluation of Class II amalgam restorations Community Dentistry and Oral Epidemiology 24(3) 207-210.

65. Otto T, \& Schneider D (2008) Long-term clinical results of chairside Cerec CAD/CAM inlays and onlays: a case series International Journal of Prosthodontics 21(1) 53-59.

66. Schulz P, Johansson A, \& Arvidson K (2003) A retrospective study of Mirage ceramic inlays over up to 9 years International Journal of Prosthodontics 16(5) 510-514.

67. Bottenberg P, Jacquet W, Alaerts M, \& Keulemans F (2009) A prospective randomized clinical trial of one bisGMA-based and two ormocer-based composite restorative systems in class II cavities: five-year results Journal of Dentistry 37(3) 198-203.

68. Plasmans PJ, Creugers NH, \& Mulder J (1998) Longterm survival of extensive amalgam restorations Journal of Dental Research 77(3) 453-460.

69. Roberts JF, \& Sherriff M (1990) The fate and survival of amalgam and preformed crown molar restorations placed in a specialist paediatric dental practice British Dental Journal 169(8) 237-244.

70. Van Nieuwenhuysen JP, D'Hoore W, Carvalho J, \& Qvist V (2003) Long-term evaluation of extensive restorations in permanent teeth Journal of Dentistry 31(6) 395-405.

71. Fontana M, \& Zero DT (2006) Assessing patients' caries risk Journal of the American Dental Association 137(9) 1231-1239.

72. Featherstone JD, Domejean-Orliaguet S, Jenson L, Wolff M, \& Young DA (2007) Caries risk assessment in practice for age 6 through adult Journal of the California Dental Association 35(10) 703-707, 710-703.

73. Domejean-Orliaguet S, Gansky SA, \& Featherstone JD (2006) Caries risk assessment in an educational environment Journal of Dental Education 70(12) 1346-1354.

74. Soderstrom U, Johansson I, \& Sunnegardh-Gronberg K (2014) A retrospective analysis of caries treatment and 
development in relation to assessed caries risk in an adult population in Sweden BMC Oral Health 14126.

75. Correa MB, Peres MA, Peres KG, Horta BL, Barros AJ, \& Demarco FF (2013) Do socioeconomic determinants affect the quality of posterior dental restorations? A multilevel approach Journal of Dentistry 41(11) 960-967.

76. Simecek JW, Diefenderfer KE, \& Cohen ME (2009) An evaluation of replacement rates for posterior resin-based composite and amalgam restorations in U.S. Navy and marine corps recruits Journal of the American Dental Association 140(2) 200-209; quiz 249.

77. Broadbent JM, Thomson WM, Boyens JV, \& Poulton R (2011) Dental plaque and oral health during the first 32 years of life Journal of the American Dental Association 142(4) 415-426.

78. Grippo JO, Simring M, \& Schreiner S (2004) Attrition, abrasion, corrosion and abfraction revisited: a new perspective on tooth surface lesions Journal of the American Dental Association 135(8) 1109-1118; quiz 1163-1105.

79. Shellis RP, \& Addy M (2014) The interactions between attrition, abrasion and erosion in tooth wear Monographs in Oral Science 25 32-45.

80. Lavigne GJ, Khoury S, Abe S, Yamaguchi T, \& Raphael K (2008) Bruxism physiology and pathology: an overview for clinicians Journal of Oral Rehabilitation 35(7) 476-494.

81. Paesani DA (2010) Introduction to Bruxism In: Paesani DA (ed) Bruxism: Theory and Practice Quintessence Publishing, London, 3-15.

82. Ganss C, Young A, \& Lussi A (2011) Tooth wear and erosion: methodological issues in epidemiological and public health research and the future research agenda Community Dental Health 28(3) 191-195.

83. Mehta SB, Banerji S, Millar BJ, \& Suarez-Feito JM (2012) Current concepts on the management of tooth wear: part 1. Assessment, treatment planning and strategies for the prevention and the passive management of tooth wear British Dental Journal 212(1) 17-27.

84. Koyano K, Tsukiyama Y, Ichiki R, \& Kuwata T (2008) Assessment of bruxism in the clinic Journal of Oral Rehabilitation 35(7) 495-508.

85. Manfredini D, Winocur E, Guarda-Nardini L, Paesani D, \& Lobbezoo F (2013) Epidemiology of bruxism in adults: a systematic review of the literature Journal of Orofacial Pain 27(2) 99-110.

86. Lobbezoo F, Ahlberg J, Glaros AG, Kato T, Koyano K, Lavigne GJ, de Leeuw R, Manfredini D, Svensson P, \& Winocur E (2013) Bruxism defined and graded: an international consensus Journal of Oral Rehabilitation 40(1) 2 -4.

87. Maluly M, Andersen ML, Dal-Fabbro C, Garbuio S, Bittencourt L, de Siqueira JT, \& Tufik S (2013) Polysomnographic study of the prevalence of sleep bruxism in a population sample Journal of Dental Research 92(Supplement 7) 97S-103S.
88. Liu B, Zhang M, Chen Y, \& Yao Y (2014) Tooth wear in aging people: an investigation of the prevalence and the influential factors of incisal/occlusal tooth wear in northwest China BMC Oral Health 1465.

89. Vasudeva G, \& Bogra P (2008) The effect of occlusal restoration and loading on the development of abfraction lesions: a finite element study Journal of Conservative Dentistry 11(3) 117-120.

90. Ausiello P, Rengo S, Davidson CL, \& Watts DC (2004) Stress distributions in adhesively cemented ceramic and resin-composite class II inlay restorations: a 3D-FEA study Dental Materials 20(9) 862-872.

91. Jiang W, Bo H, Yongchun G \& LongXing N (2010) Stress distribution in molars restored with inlays or onlays with or without endodontic treatment: a three-dimensional finite element analysis Journal of Prosthetic Dentistry 103(1) 6-12.

92. Koc D, Dogan A, \& Bek B (2010) Bite force and influential factors on bite force measurements: a literature review European Journal of Dentistry 4(2) 223-232.

93. Silva AE, Demarco FF, \& Feldens CA (2015) Oral healthrelated quality of life and associated factors in Southern Brazilian elderly Gerodontology 32(1) 35-45.

94. Crocombe LA, Broadbent JM, Thomson WM, Brennan DS, \& Poulton R (2012) Impact of dental visiting trajectory patterns on clinical oral health and oral health-related quality of life Journal of Public Health Dentistry 72(1) 36-44.

95. Da Rosa Rodolpho PA, Donassollo TA, Cenci MS, Loguercio AD, Moraes RR, Bronkhorst EM, Opdam NJ, \& Demarco FF (2011) 22-Year clinical evaluation of the performance of two posterior composites with different filler characteristics Dental Materials 27(10) 955-963.

96. Palencia L, Espelt A, Cornejo-Ovalle M, \& Borrell C (2014) Socioeconomic inequalities in the use of dental care services in Europe: what is the role of public coverage? Community Dentistry and Oral Epidemiology 42(2) 97-105.

97. Hannigan A, \& Lynch CD (2013) Statistical methodology in oral and dental research: pitfalls and recommendations Journal of Dentistry 41(5) 385-392.

98. Faggion CM Jr (2012) Is the evidence supporting dental procedures strong? A survey of Cochrane systematic reviews in oral health Journal of Evidence-Based Dental Practice 12(3) 131-134 e114.

99. Sarkis-Onofre R, Cenci MS, Demarco FF, Lynch CD, Fleming PS, Pereira-Cenci T, \& Moher D (2015) Use of guidelines to improve the quality and transparency of reporting oral health research Journal of Dentistry 43(4) 397-404.

100. Rasines Alcaraz MG, Veitz-Keenan A, Sahrmann P, Schmidlin Patrick R, Davis D, \& Iheozor-Ejiofor Z (2014) Direct composite resin fillings versus amalgam fillings for permanent or adult posterior teeth Cochrane Database of Systematic Reviews 3:CD005620.

101. Makhija SK, Gordan VV, Gilbert GH, Litaker MS, Brad Rindal D, Pihlstrom DJ, \& Qvist V (2011) Practitioner, 
patient and carious lesion characteristics associated with type of restorative material: findings from the dental practice-based research network Journal of the American Dental Association 142(6) 622-632.

102. Rosenstiel SF, Land MF, \& Rashid RG (2004) Dentists' molar restoration choices and longevity: a web-based survey Journal of Prosthetic Dentistry 91(4) 363-367.

103. Espelid I, Cairns J, Askildsen JE, Qvist V, Gaarden T, \& Tveit AB (2006) Preferences over dental restorative materials among young patients and dental professionals European Journal of Oral Sciences 114(1) 15-21.

104. Ben-Gal G, \& Weiss EI (2011) Trends in material choice for posterior restorations in an Israeli dental school: composite resin versus amalgam Journal of Dental Education 75(12) 1590-1595.

105. Demarco FF, Peres KG, \& Peres MA (2014) Life course epidemiology and its implication for oral health Brazilian Oral Research 28(1) editorial doi: 10.1590/ S1806-83242014.50000006.
106. Tyas MJ, Anusavice KJ, Frencken JE, \& Mount GJ (2000) Minimal intervention dentistry-a review. FDI Commission Project 1-97 International Dental Journal 50(1) 1-12.

107. Sjogren P (2006) Cost of composite and glass ionomer class II molar restorations and theoretical analyses of cost per year of function at public dental services in Sweden Swedish Dental Journal 30(3) 99-107.

108. Hayashi M, Haapasalo M, Imazato S, Lee JI, Momoi Y, Murakami S, Whelton H, \& Wilson N (2014) Dentistry in the 21st century: challenges of a globalising world International Dental Journal 64(6) 333-342.

109. Elderton RJ (1988) Restorations without conventional cavity preparations International Dental Journal 38(2) 112-118.

110. Lucarotti PSK, Holder RL, \& Burke FJT (2005) Analysis of an administrative database of half a million restorations over 11 years Journal of Dentistry 33(10) 791-803. 